\title{
Re-Os and Ar-Ar isotope measurements of inclusions in diamonds from the Ural Mountains: constraints on diamond genesis and eruption ages
}

\author{
F. Laiginhas ${ }^{1}$, D. G. Pearson ${ }^{2}$, D. Phillips ${ }^{3}$ R. Burgess ${ }^{4}$ and J.W. Harris ${ }^{1}$ \\ ${ }^{I}$ Department of Geographical and Earth Sciences, University of Glasgow, Glasgow G12 8QQ, UK \\ ${ }^{2}$ Department of Earth Sciences, Durham University, Durham DHI 4QE, UK \\ ${ }^{3}$ School of Earth Sciences, University of Melbourne, Melbourne, Victoria 3010, Australia \\ ${ }^{4}$ School of Earth, Atmospheric and Environmental Sciences, University of Manchester, Manchester M13 9PL, UK
}

\section{Introduction}

The occurrence of alluvial diamond placers along the western edge of the Middle and North Ural Mountains (Figure 1) has been known since 1829 (Kukharenko, 1955). The Lower Devonian (about 407-397 Ma) sedimentary deposits are mainly confined to the Takaty Formation (Brown et al., 2006) with sediment transportation, at that time, generally from the northwest (Konstantinovskii, 2003).

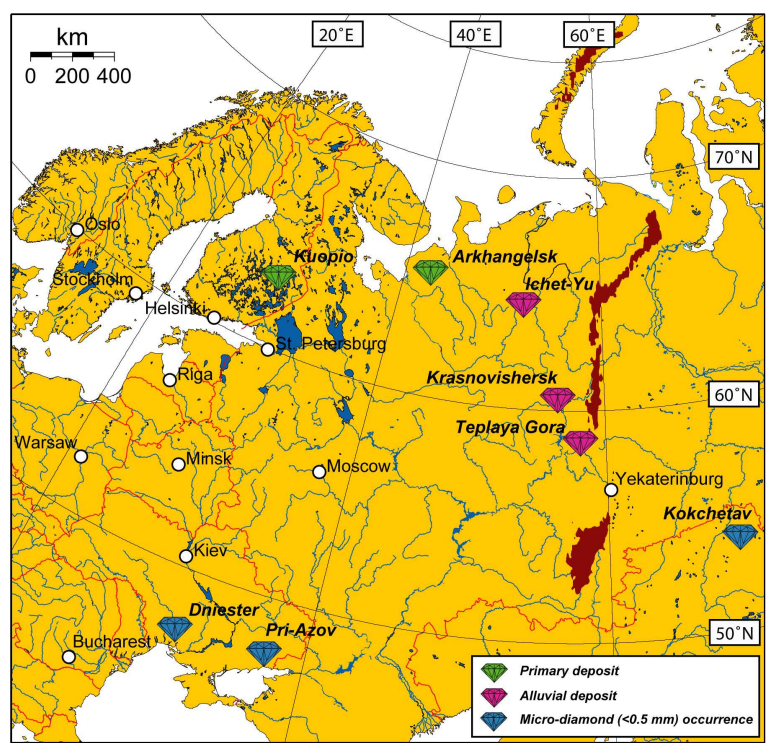

Figure 1: The location of the main primary and alluvial macro-diamond deposits and micro-diamond $(<0.5 \mathrm{~mm})$ occurrences closest to the Ural Mountains.

The primary source of the Ural diamonds is not known. In order to constrain the origin of these diamonds we carried out a detailed integrated study of both the physical and chemical properties of the diamonds and their inclusions. The Re-Os genesis ages of 20 syngenetic sulphide inclusions, recovered from 15 diamonds and the ${ }^{40} \mathrm{Ar} /{ }^{39} \mathrm{Ar}$ eruption ages of 7 syngenetic clinopyroxenes recovered from 5 diamonds are presented in this paper.

\section{Re-Os diamond genesis ages}

Eleven of the twenty sulphides coexist with eclogitic minerals, but the range of $\operatorname{Re}(87$ to $967 \mathrm{ppb}$ ) and Os (3 to $775 \mathrm{ppb})$ concentrations and the low $(\mathrm{Ni}+\mathrm{Co}) / \mathrm{Fe}$
(0.02 to 0.16 ) ratio for all sulphides, strongly indicate that this sulphide suite is entirely eclogitic (Deines and Harris, 1995; Pearson et al., 1998; Richardson et al., 2001). The sulphide inclusions are highly radiogenic with ${ }^{187} \mathrm{Os} /{ }^{188} \mathrm{Os}$ ratios between 1.28 and 24.3 and, in addition, have large ranges in ${ }^{187} \mathrm{Re} /{ }^{188} \mathrm{Os}$, from 2.3 to 804. These features should make the sulphides particularly amenable to dating. However, a single, well-correlated linear array was not obtained from all the samples. This result indicates that the Urals alluvial deposits contain more than one population of diamonds, with distinct ${ }^{187} \mathrm{Os} /{ }^{188}$ Os initial ratios.

Accordingly, the sulphide-bearing diamonds were examined to look for those that may have crystallised at the same time and hence would have shared the same temperature-time history. For this purpose FTIR was used to evaluate $\mathrm{N}$-aggregation systematics because this process is sensitive to these two parameters (Taylor et al., 1990). Assuming a mantle residence time of $1.0 \mathrm{Ga}$, a group of 8 samples defined an elongate trend adhering closely to the $1150^{\circ} \mathrm{C}$

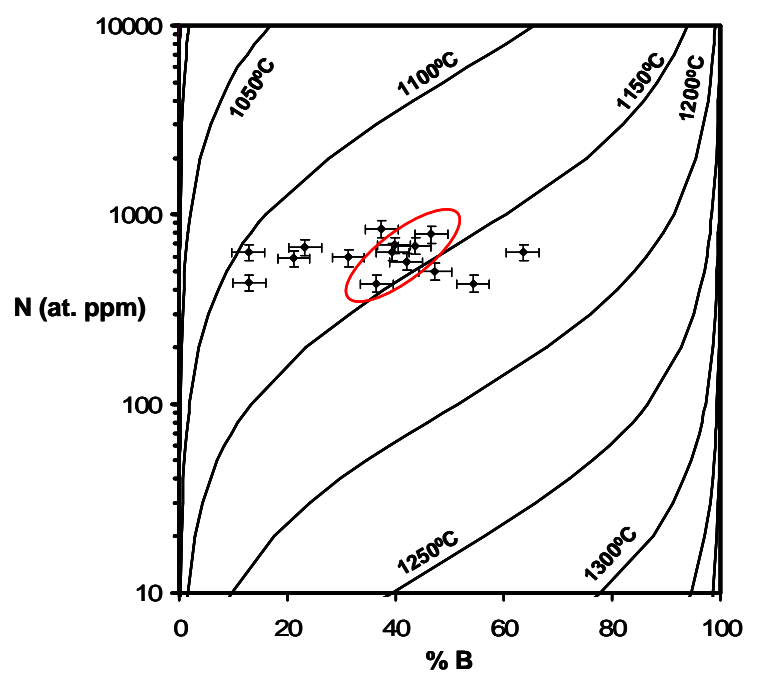

Figure 2: Total nitrogen concentration (atomic ppm) versus nitrogen aggregation state (expressed as relative percentage of the fully aggregated nitrogen B-centre) for the 15 diamonds that contained the sulphides analysed for Re-Os. Those plotting within the red circle were taken as having experienced a similar temperature-time history and hence were the sulphide inclusions used for isochron regression. Isotherms are calculated for a mantle residence time of 1.0 Ga using constants from (Taylor et al., 1990). 
isotherm (see Figure 2). A similar narrow temperature range (about $20^{\circ} \mathrm{C}$ ) was observed in an FTIR study of a suite of 59 diamonds recovered from a small single xenolith, and interpreted by Thomassot et al. (2007) as having formed during a single diamond growth event. The $1150^{\circ} \mathrm{C}$ residence temperature also agrees with geothermometry data obtained for the principal eclogitic silicate inclusions from the Urals.

Initial isochron regression of the 8 sulphides gave a genesis age of $1286 \pm 230 \mathrm{Ma}$ with an elevated initial Os isotope ratio that is typical for eclogitic diamonds (Pearson et al., 1998; Richardson et al., 2001). Attempts to reproduce other combinations of these data do not result in any isochronous relationship. The initial isochron included two sulphides that had very large uncertainties in the ${ }^{187} \mathrm{Os} /{ }^{188} \mathrm{Os}$ ratio due to their small size and low Os abundance. If these two samples are removed from the dataset, the genesis age is not affected, but there is a slight increase in the uncertainty, implying that these two samples probably belonged to this diamond population. From the six remaining samples a genesis age of $1280 \pm 310 \mathrm{Ma}$ was obtained (Figure 3).

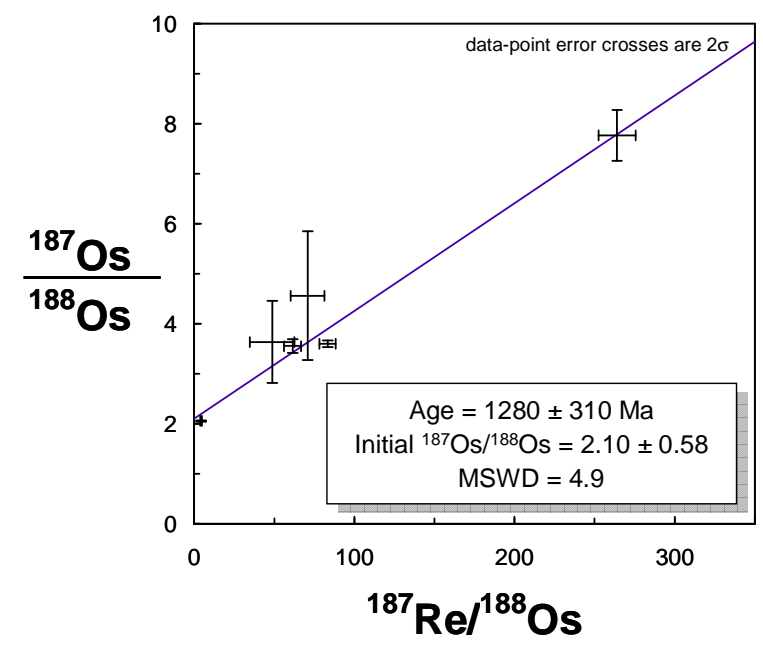

Figure 3: Re-Os isochron diagram for 6 eclogitic sulphide inclusions from the Urals. Error bars include full propagation of blank uncertainties and are at 2-sigma level.

This Re-Os isochron age is thought reliable because it includes two sulphides released from the same diamond. Moreover, the carbon and nitrogen isotopic compositions of this group of diamonds define a narrow compositional range $\left(-6.8\right.$ to $-4.2 \%$ o for $\delta^{13} \mathrm{C}$ and -6.9 to $-4.1 \%$ o for $\delta^{15} \mathrm{~N}$ ) which is consistent with an evolution from the same fluid or melt.

The age suggested by the present Re-Os systematics is within error of the 1.0 to $1.1 \mathrm{Ga}$ eclogitic sulphide inclusion Re-Os ages reported for diamonds from localities on the Kaapvaal craton (Pearson et al., 1998; Shirey et al., 2001). In a broader context, this diamond formation may be linked to a worldwide tectonothermal event at around 1.2 Ga (Pearson et al., 2007).

\section{Ar-Ar diamond eruption ages}

Seven eclogitic clinopyroxene inclusions were subjected to ${ }^{40} \mathrm{Ar} /{ }^{39} \mathrm{Ar}$ step-heating experiments, each comprising two heating increments. The "low" temperature step, heated the inclusion to the point of melting to maximise the release of any "pre-eruption" argon. This was followed by a "high" temperature fusion step which efficiently degassed any remaining ${ }^{40} \mathrm{Ar}$. From only the fusion step-heating experiments, five analyses (four diamonds) gave an average eruption age of $472 \pm 28 \mathrm{Ma}$ and two other samples (from a single stone) an average eruption age of $684 \pm 15 \mathrm{Ma}$, both at 2-sigma level (Figure 4).

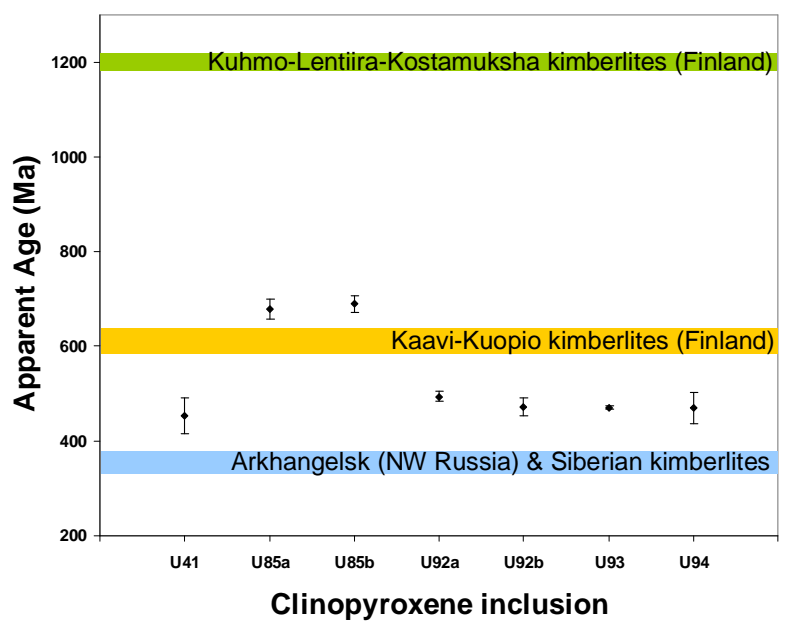

Figure 4: $40 \mathrm{Ar} / 39 \mathrm{Ar}$ laser fusion step-heating results for 7 single eclogitic clinopyroxene inclusions from the Urals. Error bars are at 2-sigma level. Also plotted are the ranges in eruption ages for known kimberlites in Russia and Finland.

Because of the possible retention of argon within the clinopyroxene inclusions all the ages in Figure 4 should be regarded as maxima. For example, Phillips et al. (2004) showed that over $70 \%$ of clinopyroxene inclusions in diamonds yielded $\mathrm{Ar}-\mathrm{Ar}$ apparent ages older but within $\sim 100$ Ma of the kimberlite eruption ages. If these results are generally applicable, then the Ural data could be linked to diamond eruption events as young as $\sim 350 \mathrm{Ma}$.

However in the present case, the ages are constrained because the diamondiferous sediments are of Emsian age (Brown et al., 2006), about 407 to 397 Ma. This Devonian age range implies that the 5 younger $\mathrm{Ar}-\mathrm{Ar}$ eruption ages do not contain a serious level of preeruption argon, indicating that the Ar-Ar age has to be particularly close to the kimberlite eruption age. The two clinopyroxene inclusions that give apparent ages over 200 Ma older, may reflect incomplete loss of preeruption argon, although more likely, because of the age difference, these specimens indicate an older and distinct eruption age.

\section{Discussion and conclusions}

At present there appears to be no clear link between the timing of the accretion of the East European Craton (EEC) and the genesis age of the Ural diamonds, even if the error range is considered. The diamond genesis event, however, might be associated with the creation within the EEC of the Central Russian Rift system at $1.3 \mathrm{Ga}$ (Artemieva, 2003). A further thermal link to trigger diamond formation at this time might be the 
extensive mantle melting event at about $1.2 \mathrm{Ga}$, identified from osmiridium grains in Urals placer deposits (Pearson et al., 2007).

The primary source of the Ural diamonds is constrained both by the main eruption age $(472 \pm 28$ $\mathrm{Ma}$ ) and that of the rocks in which the diamonds are deposited (407-397 Ma). Solely on the basis of these two ages, the Ural diamonds are not derived from present known sources in the region, because the eruption ages are either too old or seriously overlap with the date of diamond deposition. For example, these is no correspondence to eruption ages of significant kimberlites in Siberia (370-340 Ma) - see ages in Gurney et al. (2005), Finland (about 589 - 1200 Ma) (O'Brien et al., 2005; 2007) and the Arkhangelsk region (380 to $340 \mathrm{Ma}$ ) (Beard et al., 1996).

When factors such as plate tectonics, kimberlite weathering and diamond transportation are added to the story, the diamonds on the Siberian craton at 407-397 $\mathrm{Ma}$, are separated from the EEC by an ocean (Brown et al., 2006). The kimberlites of Arkhangelsk, although on the same craton, still display crater facies kimberlite, indicative of minimal erosion (Garanin et al., 2000). And the sub-economic Finnish kimberlites, although similar to the older Ar-Ar eruption age, are over 1500 $\mathrm{km}$ away. Finally, minor deposits such as those at Kokchetav in Kazakhstan and Dniester and Pri-Azov in the Ukraine, contain diamonds which are too small (<0.5 mm) (Yurk, 1973; Sobolev and Shatsky, 1990).

At present, therefore, the evidence indicates a new kimberlite/lamproite source occurring most likely in the Volgo-Uralia section of the EEC. Subsequent to eruption, river erosion gave rise to the diamondiferous sediments associated with the Takaty Formation, consisting of alluvial, deltaic and coastal-marine sediments, which accumulated on and along the eastern margin of the craton. This diamondiferous sedimentary accumulation is envisaged as being analogous to that presently found along the Namaqualand Namibian coastal belt in southern Africa. During the construction of the Ural Mountains, the diamondiferous sediments became part of the western accretion zone when the EEC united with the Siberian plate during late Devonian through to late Triassic times.

\section{References}

Artemieva, I.M., 2003. Lithospheric structure, composition, and thermal regime of the East European Craton: implications for the subsidence of the Russian platform. Earth and Planetary Science Letters, 213: 431-446.

Beard, B.L., Fraracci, K.N., Taylor, L.A., Snyder, G.A., Clayton, R.A., Mayeda, T.K. and Sobolev, N.V., 1996. Petrography and geochemistry of eclogites from the Mir kimberlite, Yakutia, Russia. Contributions to Mineralogy and Petrology, 125(4): 293-310.

Brown, D., Spadea, P., Puchkov, V., Alvarez-Marron, J., Herrington, R., Willner, A.P., Hetzel, R., Gorozhanina, Y. and Juhlin, C., 2006. Arccontinent collision in the Southern Urals. EarthScience Reviews, 79: 261-287.

Deines, P. and Harris, J.W., 1995. Sulfide inclusion chemistry and carbon isotopes of african diamonds.
Geochimica et Cosmochimica Acta, 59(15): 31733188.

Garanin, V.K., Gonzaga, G.M., Campos, J.E.G. and Kudryavtseva, G.P., 2000. A new theory of the glacial origin of diamond placers in the Ural region. Moscow University Geology Bulletin, 55(5): 54-58.

Gurney, J.J., Helmstaedt, H.H., Le Roex, A.P., Nowicki, T.E., Richardson, S.H. and Westerlund, K.J., 2005. Diamonds: crustal distribution and formation processes in time and space and an integrated deposit model. Economic Geology, 100: 143-177.

Konstantinovskii, A.A., 2003. Epochs of diamond placer formation in the precambrian and phanerozoic. Lithology and Mineral Resources, 38(6): 530-546.

Kukharenko, A.A., 1955. Diamonds of the Urals. GOSGEOL, Moscow, 515 pp.

O'Brien, H., Peltonen, P. and Vartiainen, H., 2005. Kimberlites, carbonatites and alkaline rocks. In: M. Lehtinen (Editor), Precambrian Geology of Finland - Key to the Evolution of the Fennoscandian Shield. Elsevier Science B.V., Amsterdam, pp. 605-644.

O'Brien, H., Phillips, D. and Spencer, R., 2007. Isotopic ages of Lentiira - Kuhmo - Kostomuksha olivine lamproite - Group II kimberlites. Bulletin of the Geological Society of Finland, 79: 203-215.

Pearson, D.G., Shirey, S.B., Harris, J.W. and Carlson, R.W., 1998. Sulphide inclusions in diamonds from the Koffiefontein kimberlite, S Africa: constraints on diamond ages and mantle Re-Os systematics. Earth and Planetary Science Letters, 160(3-4): 311-326.

Pearson, D.G., Parman, S.W. and Nowell, G.M., 2007. A link between large mantle melting events and continent growth seen in osmium isotopes. Nature, 449(7159): 202-205.

Phillips, D., Harris, J.W. and Kiviets, G.B., 2004. ${ }^{40} \mathrm{Ar} /{ }^{39} \mathrm{Ar}$ analyses of clinopyroxene inclusions in African diamonds: Implications for source ages of detrital diamonds. Geochimica et Cosmochimica Acta, 68(1): 151-165.

Richardson, S.H., Shirey, S.B., Harris, J.W. and Carlson, R.W., 2001. Archean subduction recorded by ReOs isotopes in eclogitic sulfide inclusions in Kimberley diamonds. Earth and Planetary Science Letters, 191(3-4): 257-266.

Shirey, S.B., Carlson, R.W., Richardson, S.H., Menzies, A., Gurney, J.J., Pearson, D.G., Harris, J.W. and Wiechert, U., 2001. Archean emplacement of eclogitic components into the lithospheric mantle during formation of the Kaapvaal Craton. Geophysical Research Letters, 28(13): 2509-2512.

Sobolev, N.V. and Shatsky, V.S., 1990. Diamond inclusions in garnets from metamorphic rocks - a new environment for diamond formation. Nature, 343(6260): 742-746.

Taylor, W.R., Jaques, A.L. and Ridd, M., 1990. Nitrogendefect aggregation characteristics of some Australasian diamonds: time-temperature constraints on the source regions of pipe and alluvial diamonds. American Mineralogist, 75: 1290-1310.

Thomassot, E., Cartigny, P., Harris, J.W. and Viljoen, K.S., 2007. Methane-related diamond crystallization in the Earth's mantle: Stable isotope evidences from a single diamond-bearing xenolith. Earth and Planetary Science Letters, 257: 362-371.

Yurk, Y.Y., 1973. Diamonds from sandy depositions of Ukraine. Naukova Dumka, Kiev. 